\title{
Giresun İlinde FV, FXIII, ACE, ApoE Gen Varyantlarmın Prevelansı ve Koroner Arter Hastalığı Profiline Etkilerinin Araştırılması
}

\author{
Ayşegül Başak AKADAM TEKER*, Erhan TEKER**, \\ Hülya YILMAZ AYDOĞAN ${ }^{* * * *}$, Aynur DAĞLAR ADAY****
}

\section{$\ddot{O} \mathbf{z}$}

Amaç: Ateroskleroz kaynaklı Koroner Arter Hastalığı (KAH), multifaktöriyel ve poligenik kompleks bir hastalıktır. Son yıllarda yapılan çalışmalarda KAH ile ilişkili bazı genetik varyantlar öne çıkmıştır. Bizim çalışmamızda da Türkiye'de Giresun ilinde yaşayanlarda KAH'na yatkınlık sağlayabilecek olan genetik profili çıarmak için kan koagülasyonu ve lipid metabolizması ile ilgili olarak dört gen bölgesi analiz edildi. Bu gen bölgeleri FV-Leiden (rs6025) (FVL), FXIII 163G> T (V34L) (rs:5985), ACE (Angiotensin-converting enzyme) (rs1799752 I/D polimorfizm), ApoE (Apolipoprotein-E) (rs7412 ve rs429358) şeklindedir.

Yöntem: Çalışmamızda 89 kontrol ve 174 hasta kullanılmıştır. ApoE gerçek zamanlı polimeraz zincir reaksiyonu (RT-PCR), FVL, FXIII, ACE PCR yöntemi kullanılarak genotipler belirlenmiştir.

Bulgular: Hasta grubunda ACE D ve ApoE e4 allel frekansları kontrol grubunda düşük saptandı (sırasıyla $\mathrm{p}=0,026$ ve $\mathrm{p}=\mathrm{0}, 015$ ). Hasta grubunda, FV A allel taşıyanlar (GA+AA) GG genotipine sahip bireylerle karşılaştırıldığında serum total kolesterol $(p=0,038)$ ve LDL-K

\section{Özgün Araştırma Makalesi (Original Research Article)}

Geliş / Received: 17.07 .2019 \& Kabul / Accepted: 16.10 .2019

${ }^{*}$ Sorumlu Yazar. Dr. Öğr. Üyesi, Giresun Üniversitesi, Tıp Fakültesi, Tıbbi Genetik Anabilim Dal, Giresun, Türkiye, E-posta: aba2904@hotmail.com ORCID ID https://orcid.org/oooo0003-3618-0560

${ }^{* *}$ Uzm. Dr., Giresun Üniversitesi, A. İlhan Özdemir Eğitim ve Araştırma Hastanesi, Kardiyoloji Kliniği, Giresun, Türkiye, E-posta: erhanteker@hotmail.com

ORCID ID https://orcid.org/o000-0002-0234-7548

**** Prof. Dr., İstanbul Üniversitesi, Aziz Sancar Deneysel Tıp Araştırma Enstitüsü, Moleküler Tıp Anabilim Dalı, İstanbul, Türkiye, E-posta: hulyayilmaz6@gmail.com ORCID ID https://orcid.org/o000-0002-8837-6664

**** Dr., İstanbul Üniversitesi, İstanbul Tıp Fakültesi, İç Hastalıkları Anabilim Dalı, Hematoloji Bilim Dall, İstanbul, Türkiye, E-posta: daglaraynur@gmail.com

ORCID ID https://orcid.org/oooo-0001-8072-0646 
( $\mathrm{p}=0,054)$ düzeyleri yüksek gözlendi. MI geçirmeyenlerde FXIII L allel varlığı \% 31,9'dur. L allel varlığı MI riskine karşı koruyucu etki göstermektedir ( $\mathrm{p}=0,06, \mathrm{OR}=0,464, \% 95 \mathrm{CI}=0,202-1,06)$.

Sonuç: Çalışmamızda araştırılan gen varyantlarının hiçbirinin direkt olarak KAH gelişimi ile ilişkisini gözlemlemedik. Ancak araştırılan gen varyantlarının dolaylı olarak KAH risk faktörlerine etkili olabilecekleri çalışmamızdan elde ettiğimiz çıkarımlardandır.

Anahtar kelimeler: KAH, FV, ApoE, ACE, FXIII.

Prevalence of FV, FXIII, ACE, ApoE Gene Variants and Effects on Coronary Artery Disease Profile in Giresun

\begin{abstract}
Aim: Atherosclerosis-induced Coronary Artery Disease (CAD) is a multifactorial and polygenic complex disease. In recent studies, some genetic variants associated with CAD have come to the fore. In our study, four gene regions were analyzed for blood coagulation and lipid metabolism in order to determine the genetic profile which may be susceptible to CAD patients in Turkey (in living Giresun). These gene regions are: FV-Leiden (rs6o25) (FVL), FXIII 163G> T (V34L) (rs: 5985), ACE (Angiotensin-converting enzyme) (rs1799752 I/D Polymorphism), ApoE rs429358).

Materials and Methods: In this study, 89 control and 174 patients were used. ApoE genotypes were determined by real time polymerase chain reaction (RT-PCR). FVL, FXIII, ACE were determined by PCR method.

Results: ACE D and ApoE e4 allele frequencies were lower in the control group $(\mathrm{p}=0.026$ and $\mathrm{p}=0.015$, respectively). Serum total cholesterol $(\mathrm{p}=0.038)$ and LDL-K $(\mathrm{p}=0.054)$ levels were higher in patients with FV A allele compared to those with GG genotype in the patient group. The presence of FXIII L allele was 31.9\% in patients without MI. The presence of $\mathrm{L}$ allele shows a protective effect against the risk of $\mathrm{MI}(\mathrm{p}=0.06, \mathrm{OR}=0.464,95 \% \mathrm{CI}=0.202-1.09)$.

Conclusion: None of the gene variants investigated in our study directly correlated with CAD development. However, the inferences we have obtained from our study, in which the gene variants investigated can indirectly affect CAD risk factors.
\end{abstract}

Keywords: KAH, FV, ApoE, ACE, FXIII.

\title{
Giriş
}

Ateroskleroz kaynaklı Koroner Arter Hastalığı (KAH), dünya çapında insidansı ve prevelansı yüksek, çeşitli çevresel ve yaşam biçimi faktörleri ile birlikte düşük penetranslı çoklu genetik varyantların neden olduğu, önemli mortalite ve morbidite 
sebebi olan multifaktöriyel ve poligenik kompleks bir hastalıktır¹. Aterotrombotik obstrüktif lezyonlarla sonuçlanan ve doku hasarına yol açan uzun vadeli ateromatöz plak oluşumu ile karakterize olan KAH için ateroskleroz ve tromboz da çok önemli iki risk faktörüdür ${ }^{2}$. KAH gelişiminde tanımlanabilir çevresel risk faktörleri vakaların yaklaşık \%80'inde tespit edilmiştir. Benzer çevre faktörlerine maruz kalan ve neredeyse benzer KAH geliştirme risk faktörlerine sahip bireylerde hastalık duyarlılı̆̆ında değişkenlik, genetik farklılıklara atfedilebilir. 2007 yılından bu yana KAH ile ilişkili genler, Genome Wide Association çalışmalarıyla (GWAS) tanımlanmıştır. KAH ile ilişkili tek nükleotid polimorfizmleri (SNP) genetik değişkenliğin belirteçleri olarak kullanılabilirler ve genel popülasyonda az bulunurlar. Bununla birlikte, tek bir SNP ile ilişkili risk, yaygın varyantların etki boyutlarının düşük olması nedeniyle yetersiz kalabilir. Bu nedenle, KAH'ın genetik analizi için çok sayıda SNP genotiplendirmesi gerekebilir3-5.

Faktör V (FV), kan koagülasyonunda anahtar rol oynayan, protrombini trombine dönüştüren ve protein C (PC) tarafından inaktive edilen $330 \mathrm{kD}$ 'lı bir proteindir ve dolayısıyla üretilen trombin miktarını modüle eder. 1 q21-25'de lokalize Faktör V geni 25 ekzondan oluşur. FV geninde yaygın olarak incelenen bir SNP FV-Leiden (FVL) (rs6025) olarak bilinen G1691A mutasyonudur6-9.

FVL mutasyonu Faktör V'in bölünmesinde aktif protein C (APC) direncine yol açar ve homozigot durumda artan kalıtsal trombofili için en önemli genetik risk faktörlerinden biri olarak bilinmektedir. R506'daki APC bölünme bölgesinin kaybından ötürü FVL, APC'nin inaktivasyonuna daha az duyarlıdır ve Faktör VIIIa inaktivasyonunda azaltılmış APC kofaktör aktivitesini ifade etmektedir. Yapılan bazı çalışmalarda FVL mutasyonunun KAH'na yatkınlık sağlayabilecek önemli bir risk faktörü olduğuna dair kanıtlar sunulmuştur8,10-12. Ancak, dünyada yapılan çalışma sonuçları arasında FVL mutasyonunun KAH gelişimine katkısıyla ilgili çelişkili sonuçlar yayınlanmıştır 13-16. Türklerde ise; bu hasta grubu için yeterli çalışma bulunmamaktadır.

Koagülasyon Faktörü XIII (FXIII), (2A ve 2B) alt ünitelerinden olşan heterotetramer yapıda 320 kDa'luk pıhtılaşma, fibrinoliz ve inflamasyonda yer alan çok fonksiyonlu bir glikoproteindir ${ }^{17}$. Aktive edilmiş faktör XIII, pıhtı stabilitesini arttırmak için 2A ve 2B alt ünitelerinden oluşan fibrini kovalent olarak çapraz bağlar ve fibrinoliz için daha dirençli sert üç boyutlu bir yapıya neden olur. FXIII ekzon 2'deki (Val34Leu) 
polimorfizmi trombotik bozukluklarla ilişkilendirilmiştir. Ancak nadir FXIII 34Leu varyantı şaşırtıcı bir şekilde Miyokard Enfraktüs (MI) dâhil olmak üzere hem venöz hem de arteryal tromboz insidansının daha düşük olmasıyla ilişkilendirilmiştir ${ }^{18-20}$. Bu koruyucu etki oldukça şaşırtıcıdır. Çünkü Leu34 varyantının daha yüksek transglutaminaz aktivitesinin, fibrin pıhtısının plazmin bozulmasına karşı artan dirençle sonuçlanması beklenir.

19q13.2'de lokalize Apolipoprotein E (ApoE) geni 299 amino asitten oluşan ApoE proteinini kodlar. Oldukça polimorfik bir yapıya sahip olan ApoE, LDL, HDL, şilomikronların oluşmasında ve kolestrolün periferik dokulardan karaciğere taşınmasında rol oynar ${ }^{21,22}$. Yapılan pek çok çalışmada ApoE geni lipoprotein metabolizmasındaki görevinden dolayı KAH ile ilişkili olabilecek en muhtemel aday genlerden biri olarak görülmüştür²3.

Renin-anjiyotensin sistemi, vasküler endotel fonksiyonu ve düz kas hücre proliferasyonunun kontrolüne ek olarak proinflamatuar sitokinlerin ve vasküler matriksin sentezini modüle ederek ateroskleroz patogenezinde kilit bir rol oynamaktadır²4. Bu sistemin ana bileşeni olan Anjiyotensin dönüştürücü enzim (ACE), 17q23'de lokalize 26 ekzon ve 25 introndan oluşan oldukça polimorfik bir gen bölgesi tarafından kodlanmaktadır. ACE kan basıncı regülasyonunda rol alır ve çeşitli fizyolojik fonksiyonları kontrol eder. ACE I / D polimorfizmi (rs4646994), intron 16 içinde 287 bp'lik Alu tekrar sekansı varlığı (I) veya yokluğu ile (D) karakterizedir ${ }^{25}$. ACE (rs4646994) polimorfizminin, metabolik sendrom, hipertansiyon, dislipidemi, glikoz seviyesi, merkezi obezite ve hipertrigliseridemi gibi çeşitli klinik bulgularla ilişkili olduğu bildirilmiştir. Ek olarak, bu genin D allelinin bir takım kardiyovasküler hastalıklar, yüksek tansiyon, kardiyomiyopati ve KAH ile pozitif ilişkisini gösteren kanitlar da vardır ${ }^{26-28}$.

Son yıllarda yapılan çalışmalarda KAH ile ilişkili bazı genetik varyantlar öne çıkmıştır. Bizim çalışmamızda da Türk toplumunda KAH’a yatkınlık sağlayabilecek olan genetik profili çıkarmak için kan koagülasyonu ve lipid metabolizması ile ilgili olarak dört gen bölgesi analiz edildi. Bu gen bölgeleri FV (rs6o25) (FVL), FXIII 163G> T (V34L) (rs:5985), ACE (Angiotensin-converting enzyme) (rs1799752 I/D polimorfizm), ApoE (rs7412 ve rs429358) şeklindedir. 


\section{Gereç ve Yöntem}

$\mathrm{Bu}$ çalışmada iki örneklem grubu kullanılmıştır. Birinci grupta 89 kişiden oluşan yüksek tansiyon, kalp rahatsızlığı hikâyesi olmayan, lipid anomalisi, metabolik rahatsızlık (DM, böbrek yetersizliği, KC yetersizliği vs.), ailede bilinen erken yaş iskemik kalp hastalığı, lipid metabolizma bozukluğu olmayan, koroner anjiogrofik olarak KAH olmayan erkek bireyler kontrol grubuna alınmıştır. İkinci grupta, Giresun Üniversitesi Prof. Dr. A. İlhan Özdemir Eğitim ve Araştırma Hastanesi Kardiyoloji Kliniği tarafından takip edilen anjiografik olarak koroner arter hastalığı tanısı konmuş 174 erkek hasta çalışmaya dâhil edilmiştir. Hasta ve kontrol grubundaki tüm bireylere proje ile ilgili bilgi verilmiş ve yazılı izinleri alınmıştır. Ayrıca, KAH risk faktörleri ile ilgili olarak Beden Kitle İndeksi $\left(\mathrm{kg} / \mathrm{m}^{2}\right)$, aile hikayesi, arteriyel hipertansiyon $(\geq 140$ mmHg sistolik kan basıncı, $\geq 90 \mathrm{mmHg}$ diastolik kan basıncı), hiperlipidemi (total kolesterol $>240 \mathrm{mg} / \mathrm{dl}$ and trigliserid >250 mg/dl) değerlendirilmiştir. Hasta ve kontrol gruplarında genotip ve allel dağılımları istatistiksel analizle incelenerek hastalık gelişiminde risk oluşturup oluşturmadıkları tespit edilmeye çalışılmıştır. Çalışmamız Giresun Üniversitesi Tıp Fakültesi Klinik Araştırmalar Etik Kurulu'ndan alınan KAEK68 sayılı etik kurul kararınca gerçekleştirilmiştir.

\section{DNA İzolasyonu}

Çalışmaya dâhil edilen bireylerden Etilen diamin tetra asetik asit (EDTA)'lı tüpe $2 \mathrm{ml}$ kan alınmıştır. Genomik DNA izolasyonu için, alınan tam kan örneğinden kit manuelinde belirtilen şekilde DNA izole edilmiştir (Roche Diagnostic, GmbH, Mannheim, Almanya). İzolasyon sonrası DNA miktar tayini $260 \mathrm{~nm}$ spektrofotometrik ölçümlerdeki absorbans oranlarına göre belirlenmiştir. ApoE mutasyonları, LightCycler Apo E Mutasyon Tespit Kiti (Roche Diagnostics, Mannheim, Almanya) ile analiz edilmiştir. Polimeraz zincir reaksiyonu ile çoğaltılan gen bölgeleri ve primerleri şu şekildedir. FV (rs6025) (FVL): F: 5'-TGC CCA GTG CTT AAC AAG ACC A-3' R: 5'-TGT TAT CAC ACT GGT GCT AA-3 ${ }^{\prime 29}$, FXIII 163G> T (V34L) :F:5' CATGCCTTTTCTGTTGTCTTC-3 R:5' TACCTTGCAGGTTGACGCCCCGGGGCACTA$3^{\prime 30}$. Surasıyla MnlI, DdeI, enzimleriyle kesime uğratılmıştır. ACE (Angiotensinconverting enzyme $)($ rs1799752 I/D polimorfizm)313 gen ürünleri II genotipi: 49obç, DD genotipi: 19obç, ID genotipi:49obç,19obç şeklinde değerlendirilmişir. Kesim ürünleri 
\%3’lik agaroz jel elektroforezi ile yürütülmüş ve UV'de görüntüleme yapılarak genotipler belirlenmiştir.

\section{İstatiksel Analiz}

$\mathrm{Bu}$ çalışmanın istatiksel analizi SPSS 20,0 paket programı kullanılarak yapılmıştır. İstatiksel anlamlılık sınırı p<0,05 olarak alınmıştır. Çalışma gruplarında Beden Kitle Indeksleri arasındaki farkın belirlenmesinde Student's t-testi, genotip ve allellerin görülme sıklığının gruplar arası farklılıklarının değerlendirilmesinde Ki kare $\left(\chi^{2}\right)$ testi kullanılmıştır. Klinik ve klinik olmayan parametrelerin allellerle karşılaştırılmasında Kruskal Wallis metodu, genotip açısından incelenmesinde ise Student's t-testi kullanılmıştır. Gruplar arası risk etkeninin belirlenmesi için Odds oranı (OR) ve \% 95 güven aralığı (\% 95 CI) verilmiştir. Allel frekansı hesaplamalarında gen sayma yöntemi kullanılmıştır.

\section{Bulgular}

Giresun Üniversitesi Prof. Dr. A İlhan Özdemir Eğitim ve Araştırma Hastanesi Kardiyoloji Kliniği’nde takip edilen 174 koroner arter hastası ve 89 gönüllü sağlıklı kontrolden oluşan çalışma grupları arasında karşılaştırmalar yapılmıştır. Çalışmamızın gruplarına ait demografik bilgiler ve biyokimyasal parametrelere ait bulgular Tablo1'de verilmiştir. Hasta grubunda sigara kullanımı ve açlı kan şekeri kontrol grubuna kıyasla yüksek gözlenmiştir (sırasıyla $\mathrm{p}=0,053$ ve $\mathrm{p}=0.001$ ). Diğer biyokimyasal ve klinik parametreler açısından gruplar arasında farklılık bulunmamıştır ( $\mathrm{p}>0.05)$. 
Tablo 1. Çalışma gruplarının karakteristik özellikleri

\begin{tabular}{|l|l|l|l|}
\hline \multicolumn{2}{|c|}{ Kontrol (n=89) } & \multirow{2}{*}{ KAH Hasta (n=174) } & \multirow{2}{*}{} \\
\cline { 1 - 3 } & & & \\
\hline Yaş (yıl) & $56,81 \pm 0,90$ & $56,93 \pm 0,63$ & 0,911 \\
\hline BKİ (kg/m²) & $25,16 \pm 0,77$ & $26,06 \pm 0,60$ & 0,860 \\
\hline Total-Kolesterol (mg/dL) & $191,48 \pm 5,69$ & $181,74 \pm 3,86$ & 0,157 \\
\hline Trigliserid (mg/dL) & $163,11 \pm 22,16$ & $144,72 \pm 5,29$ & 0,281 \\
\hline HDL-K (mg/dL)) & $42,11 \pm 1,72$ & $42,19 \pm 0,80$ & 0.594 \\
\hline LDL-K (mg/dL) & $118,30 \pm 4,99$ & $111,92 \pm 2,87$ & 0,276 \\
\hline VLDL-K (mg/dL) & $27,98 \pm 3,44$ & $26,43 \pm 1,09$ & 0,579 \\
\hline SKB (mmHg) & $128,84 \pm 1,99$ & $126,39 \pm 1,46$ & 0,328 \\
\hline DKB (mmHg) & $76,57 \pm 1,51$ & $76,62 \pm 0,92$ & 0,977 \\
\hline Açlık kan şekeri (mg/dL) & $89,36 \pm 2,09$ & $112,78 \pm 45,91$ & 0,001 \\
\hline Sigara Kullanımı (\%) & $\% 52,0$ & $\% 67,3$ & 0,035 \\
\hline EF & - & $50,48 \pm 1,02$ & - \\
\hline İlk MI yaş & & $50,68 \pm 0,62$ & - \\
\hline Tip 2 Diabet varlığı (\%) & - & $\% 43,1$ & - \\
\hline
\end{tabular}

Tablodaki değerler Ortalama \pm Standart hata ve "yüzde” olarak verilmiştir.

BKİ: Beden Kütle İndeksi, n: kişi sayısı, KAH: Koroner arter hastalığı, SKB: sistolik kan basıncı, DKB: Diastolik kan basıncı, EF: Ejeksiyon-Fraksiyon

Çalışma gruplarında incelenen polimorfizlerin dağılımları Tablo 2'de verilmiştir. Hasta grubunda Faktor V G>A ve F13 V>L genotip dağılımı Hardy-Weinberg Eşitliği (HWE)'ne uyumlu değildir ( $\mathrm{p}<0,05)$. Diğer polimorfizmlere ait dağılımlar ise hasta ve kontrol gruplarında HWE'ne uyumlu gözlenmiştir ( $p>0,05)$. Hasta grubunda, ACE D ve ApoE4 allel frekansları kontrol grubuna göre düşük saptanmıştır (sırasıyla $p=0,026$ ve $\mathrm{p}=0,015)$. 
Tablo 2. Çalışma gruplarında incelenen polimorfizlerin dağılımları

\begin{tabular}{|c|c|c|}
\hline & Study Groups & \\
\hline FactorV G $>$ A Genotip & Kontrol $(\mathrm{n}=89)$ & KAH hasta $(\mathrm{n}=174)$ \\
\hline GG & $71(79,8 \%)$ & $144(82,8 \%)$ \\
\hline$\overline{\mathbf{A A}}$ & 0 & $5(2,9 \%)$ \\
\hline GA & $18(20,2 \%)$ & $25(14,4 \%)$ \\
\hline HWE & $\mathrm{p}>0,05$ & $\mathrm{p}<0,05$ \\
\hline \multicolumn{3}{|l|}{ FactorV G>A Allel } \\
\hline$\overline{\mathbf{G}}$ & $160(89,89 \%)$ & $313(89,94 \%)$ \\
\hline$\overline{\mathbf{A}}$ & $18(10,11 \%)$ & $35(10,06 \%)$ \\
\hline \multicolumn{3}{|l|}{ ACE I > D Genotip } \\
\hline II & $11(12,4 \%)$ & $29(16,7 \%)$ \\
\hline$\overline{D D}$ & $40(44,9 \%)$ & $54(31,0 \%)$ \\
\hline ID & $38(42,7 \%)$ & $91(52,3 \%)$ \\
\hline HWE & $\mathrm{p}>0,05$ & $\mathrm{p}>0,05$ \\
\hline \multicolumn{3}{|l|}{ ACE I > D Allel } \\
\hline $\mathbf{I}$ & $60(33,71 \%)$ & $149(48,82 \%)$ \\
\hline $\mathbf{D}$ & $118(66,29 \%)$ & $199(57,18 \%)$ \\
\hline \multicolumn{3}{|l|}{ ApoE Genotip } \\
\hline E2E2 & $\mathrm{O}$ & $\mathrm{O}$ \\
\hline E2E3 & $7(7,9 \%)$ & $27(15,5 \%)$ \\
\hline E2E4 & $1(1,1 \%)$ & $2(1,1 \%)$ \\
\hline E3E3 & $58(65,2 \%)$ & $122(70,1 \%)$ \\
\hline E3E4 & $19(21,3 \%)$ & $19(10,9)$ \\
\hline E4E4 & $4(4,5 \%)$ & $4(2,3 \%)$ \\
\hline HWE & $\mathrm{p}>0,05$ & $\mathrm{p}>0,05$ \\
\hline \multicolumn{3}{|l|}{ ApoE Allel } \\
\hline E2 & $8(4,49 \%)$ & $29(8.33 \%)$ \\
\hline E3 & $142(79,78 \%)$ & $290(83,33 \%)$ \\
\hline E4 & $28(15,73 \%)^{*}$ & $29(8,33 \%)$ \\
\hline \multicolumn{3}{|l|}{ F13 Genotip } \\
\hline$\overline{\mathbf{V V}}$ & $62(69,7 \%)$ & $107(61,5 \%)$ \\
\hline $\mathbf{L L}$ & $2(2,2 \%)$ & $15(8,6 \%)$ \\
\hline VL & $25(28,1 \%)$ & $52(29,9 \%)$ \\
\hline
\end{tabular}




\begin{tabular}{|l|l|l|}
\hline HWE & $\mathrm{p}>0,05$ & $\mathrm{p}<0,05$ \\
\hline F13 Allel & & \\
\hline V & $149(83,71 \%)$ & $266(76,44 \%)$ \\
\hline L & $118(16,29 \%)$ & $82(23,56 \%)$ \\
\hline
\end{tabular}

HWE, Hardy-Weinberg Eşitliği; n, örnek sayısı.

* $\mathrm{p}=0,026$ Kikare $=4,96)$

** $\mathrm{p}=\mathrm{0}, 015($ Kikare $=5,944)$

Çalışma gruplarında FVL mutasyonunun lipid profiline olan etkileri tablo3'de verilmiştir. Hasta grubunda FV A allel taşıyanlarda GG genotip taşıyanlarla karşılaştırıldığında serum total kolesterol $(p=0,038)$ ve LDL-kolesterol $(p=0,054)$ düzeyleri yüksek gözlenirken, açlık kan şekeri değerleri düşük tespit edilmiştir $(p=0,008)$.

Tablo 3. FV G>A genotiplerinin çalışma gruplarında serum lipid profili, kan basınçları ve beden kitle indeksi üzerine etkisi

\begin{tabular}{|c|c|c|c|c|}
\hline \multirow[b]{3}{*}{ Parametre } & \multicolumn{4}{|l|}{ GRUP } \\
\hline & \multicolumn{2}{|l|}{ KONTROL } & \multicolumn{2}{|l|}{ HASTA } \\
\hline & GG & A Allel & $\overline{G G}$ & A Allel \\
\hline BKİ $\left(\mathbf{k g} / \mathbf{m}^{2}\right)$ & $25,31 \pm 0,74$ & $23,99 \pm 4,76$ & $26,26 \pm 0,95$ & $25,78 \pm 0,61$ \\
\hline Total-K (mg/dL) & $192,76 \pm 6,22$ & $186,71 \pm 14,02$ & $178,13 \pm 3,57$ & $199,41 \pm 14,37^{*}$ \\
\hline TG (mg/dL) & $171,29 \pm 27,86$ & $132,82 \pm 14,06$ & $144.61 \pm 5.69$ & $145,24 \pm 14,27$ \\
\hline HDL-K (mg/dL) & $42,65 \pm 1,88$ & $40,0 \pm 4,27$ & $41,60 \pm 0,83$ & $39,17 \pm 2,40$ \\
\hline LDL -K (mg/dL) & $120,91 \pm 5,30$ & $108,09 \pm 13,24$ & $109,42 \pm 2,99$ & $124,17 \pm 8,25^{* *}$ \\
\hline VLDL -K (mg/dL) & $28,83 \pm 4,26$ & $24,60 \pm 2,73$ & $26,21 \pm 1,12$ & $27,41 \pm 3,33$ \\
\hline SKB (mmHg) & $128,62 \pm 2,09$ & $129,71 \pm 5,63$ & $125,94 \pm 1.55$ & $128,50 \pm 4,09$ \\
\hline DKB (mmHg) & $76,30 \pm 1,55$ & $77,65 \pm 4,44$ & $76,15 \pm 0.95$ & $78,83 \pm 2,80$ \\
\hline $\begin{array}{l}\text { Açlık kan şekeri } \\
\text { (mg/dL) }\end{array}$ & $90,74 \pm 2,36$ & $84,45 \pm 4,37$ & $115,35 \pm 6,41$ & $94,50 \pm 4,04^{* * *}$ \\
\hline
\end{tabular}

Tablodaki değerler Ortalama \pm Standart sapma olarak verilmiştir.

${ }^{*}, \mathrm{p}=0,008 ;{ }^{* *}, \mathrm{p}=0,054 ;{ }^{* *}, \mathrm{p}=0,038$.

BKI: Beden Kütle İndeksi, n: kişi sayısı, KAH: Koroner arter hastalığı, SKB: sistolik kan basıncı, DKB: Diastolik kan basıncı 
Çalışma gruplarında ACE I/D polimorfizminin serum lipid profili, BKİ ve kan basınçları üzerine olan etkisi tablo 4'de verilmiştir. Hasta grubunda ACE D allel taşıyanlarda II genotip taşıyanlarla karşılaştırıldığında Beden Kitle İndeksi değerleri düşük bulunmuştur ( $\mathrm{p}=0,007)$.

Tablo 4. ACE I>D genotiplerinin çalışma gruplarında serum lipid profili, kan basınçları ve beden kitle indeksi üzerine etkisi

\begin{tabular}{|c|c|c|c|c|}
\hline \multirow[b]{3}{*}{ Parametre } & \multicolumn{4}{|l|}{ GRUP } \\
\hline & \multicolumn{2}{|l|}{ KONTROL } & \multicolumn{2}{|l|}{ HASTA } \\
\hline & II & D Allel & II & D Allel \\
\hline BKÍ (kg/m²) & $25,71 \pm 1,90$ & $24,99 \pm 0.87$ & $27,80 \pm 0,20$ & $25,75 \pm 0,69^{*}$ \\
\hline Total-K (mg/dL) & $206,13 \pm 15,82$ & $189,85 \pm 6,09$ & $189,72 \pm 7,89$ & $180,11 \pm 4,36$ \\
\hline TG (mg/dL) & $160,50 \pm 24.46$ & $163.40 \pm 24,51$ & $136,07 \pm 11,76$ & $146,50 \pm 5,91$ \\
\hline HDL-K (mg/dL) & $39.83 \pm 4,94$ & $42,40 \pm 1,85$ & $41,84 \pm 2,03$ & $41,06 \pm 0,88$ \\
\hline LDL -K (mg/dL) & $132,33 \pm 13,02$ & $116,54 \pm 5,37$ & $120,10 \pm 5,49$ & $110,25 \pm 3,26$ \\
\hline VLDL -K (mg/dL) & $23,00 \pm 3,14$ & $28,41 \pm 3,73$ & $25,50 \pm 2,89$ & $26,62 \pm 1,19$ \\
\hline SKB (mmHg) & $122,00 \pm 19,89$ & $129,74 \pm 2,10$ & $124,48 \pm 2,74$ & $126,77 \pm 1,66$ \\
\hline DKB (mmHg) & $74,00 \pm 3,79$ & $76,91 \pm 1,64$ & $74,31 \pm 0,05$ & $77,08 \pm 1,03$ \\
\hline Açlık kan şekeri (mg/dL) & $98,80 \pm 7,42$ & $88,31 \pm 2,15$ & $118,73 \pm 10,33$ & $111,00 \pm 6,76$ \\
\hline
\end{tabular}

Tablodaki değerler Ortalama \pm Standart sapma olarak verilmiştir.

BKI: Beden Kütle İndeksi, n: kişi sayısı, KAH: Koroner arter hastalı̆̆ı, SKB: sistolik kan basıncı, DKB: Diastolik kan basıncı

Çalışma gruplarında ApoE ve FXIII gen varyantlarının lipid profili, BKI ve kan basınçları üzerine etkisi gözlenmemiştir. 


\section{Tartışma}

Dünya Sağlık Örgütünün verilerine göre halen gelişmiş ve gelişmekte olan ülkelerde en önemli ölüm nedenlerinin başında aterosklerotik KAH gelmektedir ${ }^{2}$. Bugünkü bilgilerimize göre, endotel disfonksiyonu, inflamasyon, anormal lipoprotein ve homosistein metabolizması gibi olayların yanı sıra disfonksiyonel pıhtılaşma ve fibrinoliz de $\mathrm{KAH}$ patogenezinde anahtar rol oynamaktadır33,34. Aterosklerotik plak oluşumunun ve gelişiminin ana adımları iyi araştırılmış olsa da, yeni moleküllerin araştırılması ve ateroskleroz mekanizmasının belirlenmesi, yeni tedavi stratejilerinin geliştirilmesi için oldukça önem arz etmektedir. Bu nedenle aterosklerotik süreçte etkili olabileceğini düşündüğümüz FV (rs6025) (FVL), FXIII 163G> T (V34L), ACE (Angiotensin-converting enzyme) (rs1799752 I/D polimorfizm), ApoE (rs7412 ve rs429358) dört gen bölgesindeki varyantların Türk toplumundaki yaygınlığını ve KAH ile olan ilişkisini belirlemeyi amaçladık.

Trombotik risk ile ilişkilendirilmiş olan FV geninin yaygın mutasyonlarından olan FVL mutasyonu ve KAH ile ilişkili olarak literatürde çelişkili sonuçlar bulunmaktadır ${ }^{14,35}$. Bizim ülkemizde yapılmış olan bir çalışmada; Özbek ve arkadaşları ${ }^{36}$ Türkiye’nin farklı bölgelerindeki 120 sağlıklı bireyde 9,16'lık FVL taşıııı oranı ve \% 4,5'lik bir allel sıklı̆̆ı bildirmişlerdir. Bizim çalışmamızın sonuçlarına göre sağlıklı kontrollerdeki taşıyıcılık oranı 20,2 ve allel sıklığı 10,11'dir. Bu farklılığın üç kıtanın ortasında yer alan Türkiye'nin kendisine ait bir coğrafyaya sahip olması ve Karadeniz bölgesinde (Giresun) Kuzey Avrupadakine benzer bir şekilde FVL prevelansının daha yüksek gözlemlenmesinden kaynaklandığını düşünmekteyiz. Ayrıca FV A alleli varlığı serum lipoprotein düzeylerini etkileyerek hasta grubundaki yüksek total kolesterol $(p=0,038)$ ve LDL-K ( $\mathrm{p}=0,054)$ düzeyleri ile ilişkilidir. Bu nedenle lipid profili üzerine olan olumsuz etkisi göz önüne alındığında A alleline sahip olmanın KAH açısından bir risk faktörü olduğu söylenebilir.

Pıhtı stabilitesini belirleyerek pıhtılaşma kademesinin son basamağında kilit bir rol oynayan kan pıhtılaşma faktörü XIII (FXIII)'ün (rs5985) polimorfizmi G > T baz değişimi valin (V) lösin (L) aminoasit değişimi ile sonuçlanır. FXIII Val34Leu varyantının KAH ve/veya MI ile ilişkisine dair literatürde çelişkili sonuçlar yer almaktadır. Bu çelişkili sonuçlar etnik grup, cinsiyet örneklem miktarı gibi çeşitli

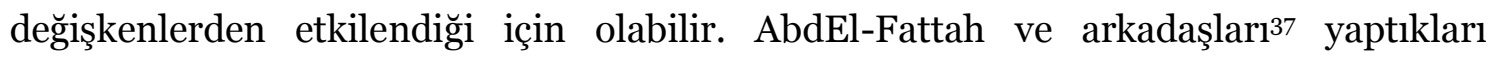


çalışmalarında FXIII VL ve LL genotipi (L allelinin) 4 kat artmış MI riski ile ilişkili olduğunu bildirmişlerdir $2007^{38}$ ve $2014^{39}$ yıllarında yapılmış olan iki önemli metaanalizde bu varyantın MI'a karşı koruyucu olduğu bildirilmiştir. Hançer ve arkadaşları'nın ${ }^{40}$ Türk hastalarda yapmış olduğu çalışmada da FXIII Val34Leu polimorfizminin MI’a karşı koruyucu etkisi rapor edilmiştir. Bizim çalışmamızın sonuçlarıda Hançer ve arkadaşlarının çalışmasına benzer şekildedir. FXIII MI geçirmeyenlerde L allel varlığı \% 31,9'dur. L allel varlığı MI riskine karşı koruyucu etki göstermektedir ( $\mathrm{p}=0,06, \mathrm{OR}=0,464, \% 95 \mathrm{CI}=0,202-1,06)$.

Ateroskleroz ile ilişkili olarak çalışılan genlerden ACE geni mutasyon insidansının yüksek olduğu gösterilmiştir. Sabbagh ve arkadaşlarının²4 yaptıkları çalışmada 133 sağlıklı donörde ACE (rs4646994) polimorfizmi D / D, I / D ve I / I genotiplerinin prevalansını sırasıyla (\% 39,1, 45,1 ve 15,8 )ve D ve I alel sıklığını ise (\% 61,7 , 38,3) olarak bildirmişlerdir. AlBacha ve arkadaşlarının ${ }^{41}$ hipertansif hiperkolesterolemik hastalarda yaptıkları çalışma D allel frekansı (97,7\%) ve genotip prevelansı I/I (2,1\%) D/D (54,2\%) şeklindedir ve Sabbagh ve arkadaşlarının yaptıkları çalışma ile uyumludur. Bizim çalışmamızın sonuçları da AlBacha ${ }^{41}$ ve Sabbagh ${ }^{24}$ 'ın çalışmalarının sonuçları ile uyumluluk göstermektedir.

Apolipoprotein E (ApoE), lipoprotein metabolizması ve kardiyovasküler hastalıkta önemli rol oynamaktadır ${ }^{22}$. Yapılan çalışmalarda ApoE ve KAH ilişkisi ile ilgili çelişkili sonuçlar yayınlanmıştır. Bu çelişkili sonuçların en büyük nedeni etnik gruplardır. Xu ve arkadaşlarının yapmış oldukları meta analiz sonuçlarına göre ApoE $\varepsilon 3 / 4$ ve $\varepsilon 4 / 4$ varyant genotipleri sırasıyla \% 22 ve \% 45 oranında artmış KAH riskiyle ilişkili olarak görülürken ${ }^{42,43}$ daha önce Türk toplumunda yapılmış olan iki çalışmada da ApoE geni ve KAH arasında anlamlı bir ilişki bulunmadığı bildirilmiştir. Bizim çalışmamızın sonuçları da Aydoğan44 ve Arslan İnce'nin 45 çalışmalarının sonuçlarıyla benzer özellik göstermektedir. Çalışmadaki diğer bir bulgumuz e2 alleli taşıyanlarda stent varlığının daha az gözlenmesi şeklindedir (\% 11,5), bu durum e2 alleline sahip olmanın stent varlığı açısından koruyucu özelliğe sahip olduğunu düşündürmektedir ( $p=0,05$, $\mathrm{OR}=0,40,95 \% \mathrm{CI}=0,15-1,02)$. MI geçirenlerde e2 allel varlığ $\%$ 9,2 olarak bulunmuştur, MI geçirmeyenlerde ise bu oran \% 34,22'dir. e2 allel varlığı MI riskine karşı koruyucu etki göstermektedir ( $\mathrm{p}=0,001, \mathrm{OR}=0,2 \% 95 \mathrm{CI}=0,07-0,5)$. Sonuçlarımız Fawzy ve arkadaşları ile uyumluluk göstermektedir ${ }^{46}$. Ayrıca, EF $<50$ olanlarda e4 allel 
varlığı \% 2,9 olarak bulunmuştur. Dolayısıyla e4 allel varlığı bu açıdan koruyucu etki göstermektedir ( $\mathrm{p}=0,002, \mathrm{OR}=0,07, \% 95 \mathrm{CI}=0,01-0,6)$.

\section{Sonuç}

Sonuç olarak; çalışmamızda lojistik regresyon analizi sonuçlarına göre araştırılan gen varyantlarının hiçbirinin direkt olarak KAH gelişimi ile ilişkisini gözlemlemedik. Diğer yandan araştırılan gen varyantlarının dolaylı olarak KAH risk faktörlerine etkili olabilecekleri çalışmamızdan elde ettiğimiz çıkarımlardandır. Çalışmamızdan elde ettiğimiz sonuçlara göre bu gen bölgelerindeki varyantların KAH patogenezine katkı sunması ya da koruyucu etki sağladığının tam olarak anlaşılabilmesi için daha büyük örneklem grubunda çalışmanın tekrarlanmayı hak ettiğini düşünmekteyiz.

\section{KAYNAKÇA}

1. Mozaffarian D, Benjamin EJ, Go AS, et al. American Heart Association statistics committee; stroke statistics subcommittee. Executive summary: heart disease and stroke statistics-2016 update: A report from the American Heart Association. Circulation. 2016;133(4):447-454.

2. Stranger BE, Forrest MS, Dunning M, et al. Relative impact of nucleotide and copy number variation on gene expression phenotypes. Science. 2007;315(5813):848853.

3. Peden JF, Farrall, M. Thirty-five common variants for coronary artery disease: the fruits of much collaborative labour. Hum. Mol. Genet. 2011;20(R2):R198-205.

4. Wray NR, Goddard ME. Multi-locus models of genetic risk of disease. Genome Med. 2010;2(2):10

5. Consortium IKC. Large-scale gene-centric analysis identifies novel variants for coronary artery disease. PLoS Genet. 2011;7(9):e1002260.

6. Mann KG, Kalafatis M. Factor V. A combination of Dr Jekyll and Mr Hyde. Blood. 2003;10:20-30.

7. Camire RM, Bos MH. The molecular basis of factor V and VIII procofactor activation. J Thromb Haemost. 2009;7(12):1951-1.

8. Castoldi E, Brugge JM, Nicolaes GA, Girelli D, Tans G, Rosing J. Impaired APC cofactor activity of Factor $\mathrm{V}$ plays a major role in the APC resistance associated with 
the Factor V Leiden (R506Q) and R2 (H1299 R) mutations. Blood. 2004;103:41734179 .

9. Tang L, Hu Y. Ethnic diversity in the genetics of venous thromboembolism. Thromb Haemost. 2015;114(5):901-909.

10. Var A, Utuk O, Akcali S, Sanlidag T, Uyanik BS, Dinc G. Impact of hemostatic gene single point mutations in patients with nondiabetic coronary artery disease. $\mathrm{Mol}$ Biol Rep. 2009;36(8):2235-2243.

11. Taymaz H, Erarslan S, Oner ET, Alkan T, Agirbasli M, Kirdar B. Sequence variations within the genes related to hemostatic imbalance and their impact on coronary artery disease in Turkish population. Thromb Res. 2007;119(1):55-62.

12. Thorelli E, Kaufman RJ, Dahlback B. Cleavage of Factor V at Arg 506 by activated protein $\mathrm{C}$ and the expression of anticoagulant activity of Factor V. Blood. 1999;93(8):2552-2558.

13. Boroumand M, Pourgholi L, Ziaee S, Anvari MS, Jalali A, Goodarzynejad H. The association between Factor V Leiden with the presence and severity of coronary artery disease. Clin Biochem. 2014;47(6):356-360.

14. Amara A, Mrad M, Sayeh A, et al. Association of FV G1691A Polymorphism but not A4070G with coronary artery disease. Clinical and Applied Thrombosis/Hemostasis. 2018;24(2):330-337.

15. Gardemann A, Arsic T, Katz N, Tillmanns H, Hehrlein FW, Haberbosch W. The factor II G20210A and factor V G1691A gene transitions and coronary heart disease. Thromb Haemost. 1999;81(2):208-213.

16. Irani Hakime N, Tamim H, Elias G, et al. Factor V R506Q mutation-Leiden: an independent risk factor for venous thrombosis but not coronary artery disease. $J$ Thromb Thrombolysis. 2001;11(2):111-116.

17. Gemmati D, Occhionorelli S, Tisato V, et al. Inherited genetic predispositions in F13A1 and F13B genes predict abdominal adhesion formation: identification of gender prognostic indicators. Sci Rep. 2018;8:16916.

18. Franco RF, Reitsma PH, Lourenço D, et al. Factor XIII Val34Leu is a genetic factor involved in the etiology of venous thrombosis. Thromb. Haemost. 1999;81(5):6769. 
19. Ansani L, Marchesini J, Pestelli G, et al. F13A1 gene variant (V34L) and residual circulating FXIIIA levels predict short-and long-term mortality in acute myocardial infarction after coronary angioplasty. Int. J. Mol. Sci. 2018;19(9): 2766.

20. Balogh L, Katona É, Mezei ZA, et al. Effect of factor XIII levels and polymorphisms on the risk of myocardial infarction in young patients. Mol and Cell Biochem. 2018;448(1-2):199-209.

21. Mahley RW, Rall SC Jr. Apolipoprotein E: far more than a lipid transport protein. Annual review of genomics and human genetics. 2000;1:507-537.

22. Luo JQ, Ren H, Banh HL, et al.The associations between Apolipoprotein E Gene Epsilon2/Epsilon3/Epsilon4 polymorphisms and the risk of coronary artery disease in patients with type 2 diabetes mellitus. Front Physiol. 2017;8:1031.

23. Zheng YM, Sun R, Li XY. Relationship between ApoE gene polymorphism and type 2 diabetes mellitus with its cardiovascular complications in Chinese. Chin. J. Endocrinol. Metab. 1998;14,11-14.

24. AlBacha JA, Khoury M, Mouawad C, et al. High incidence of ACE/PAI-1 in Association to a Spectrum of Other Polymorphic Cardiovascular Genes Involving PBMCs proinflammatory cytokines in hypertensive hypercholesterolemic patients: reversibility with a combination of ACE inhibitor and statin. PLoS One. 2015;10(5):e0127266.

25. Dhar S, Ray S, Dutta A, Sengupta B, Chakrabarti S. Polymorphism of ACE gene as the genetic predisposition of coronary artery disease in Eastern India. Indian Heart J. 2012;64(6):576-581.

26. Xi B, Ruiter R, Chen J, Pan H, Wang Y, Mi J. The ACE insertion/deletion polymorphism and its association with metabolic syndrome. Metabolism. 2012;61(6):891-897.

27. Choudhury I, Jothimalar R, Patra AK. Angiotensin converting enzyme gene polymorphism and its association with hypertension in South Indian population. Indian J Clin Biochem. 2012;27(3):265-279.

28. Kandpal V, Sachdeva MP, Saraswathy KN. An assessment study of CVD related risk factors in a tribal population of India. BMC Public Health. 2016;16(1):434.

29. Weingarz L, Schindewolf M, Schwonberg J, et al. Thrombophilia and risk of VTE recurrence according to the age at the time of first VTE manifestation. Vasa. 2015;44(4):313-3. 
30. Khare P, Raj V, Chandra S, Agarwal S. Quantitative and qualitative assessment of DNA extracted from saliva for its use in forensic identification. J.Forensic Dent. Sci. 2014;6:81-85.

31. Rigat B, Hubert C, Alhenc Gelas F, Corvol P, Soubrier F. An insertion deletion polymorphism in the angiotensin I-converting enzyme gene accounting for half the variance of serum enzyme levels. J Clin Invest. 1990;86:1343-1346.

32. World Health Organization. The 10 Leading Causes of death in the from:http://www.who.int/mediacentre/factsheets/fs310/en/ 2014. Yayınlanma tarihi 2014. Erişim tarihi 2016.

33. Barquera S, Pedroza TA, Medina C, et al. Global overview of the epidemiology of atherosclerotic cardiovascular disease. Arch. Med.Res. 2015;46(5):328-338.

34. Sakamuri SSVP, Higashi Y, Sukhanov S, et al. TRAF3IP2 mediates atherosclerotic plaque development and vulnerability in ApoE mice.

Atherosclerosis. 2016;19(16):30206-30214.

35. Eitzman DT, Westrick RJ, Shen Y, et al. Homozygosity for Factor V Leiden leads to enhanced thrombosis and atherosclerosis in mice. Circulation. 2005;111:1822-1825.

36. Ozbek U, Tangün Y. Frequency of Factor V Leiden (Arg506Gln) in Turkey. Br $J$ Haematol. 1997;97(2):504-505.

37. El-Fattah AAA, Sadik NAH, Sedrak H, Battah A, Nabil M. Association of genetic variants of hemostatic genes with myocardial infarction in Egyptian patients. Gene. 2018;641:212-219.

38. Vokó Z, Bereczky Z, Katona É, Ádány R, Muszbek L. Factor XIII Val34Leu variant protects against coronary artery disease. A meta-analysis.Thromb Haemost. 2007;97(3):458-463.

39. Wang G, Zou Z, Ji X, Ni Q, Ma Z. Factor XIII-A Val34Leu polymorphism might be associated with myocardial infarction risk: an updated meta-analysis. Int $J$ Clin Exp Med 2014;7(12):5547-5552.

40. Hancer VS, Diz KR, Bilge AK, et al. The Association Between Factor XIII Val34Leu polymorphism and early myocardial infarction. Circ $J .2006 ; 70(3): 239-242$.

41. Sabbagh AS, Otrock ZK, Mahfoud ZR, Zaatari GS, Mahfouz RA. Angiotensinconverting enzyme gene polymorphism and allele frequencies in the Lebanese population: prevalence and review of the literature. Mol Biol Rep. 2007;34(1):4752. 
42. Xu M, Zhao J, Zhang Y, et al. Apolipoprotein E gene variants and risk of coronary heart disease: a meta-analysis. Biomed Res Int. 2016;3912175.

43. Zhao QR, Lei YY, Li J, Jiang N, Shi JP. Association between apolipoprotein E polymorphisms and premature coronary artery disease: a meta-analysis. Clin Chem Lab Med. 2017;55(2):284-298.

44. Yilmaz AH, Isbir S, Kurnaz O, Gormus U, Isbir T. Associations of Lipoprotein Lipase S447X and Apolipoprotein E Genotypes with Low-density Lipoprotein Subfractions in Turkish patients with coronary artery disease. In vivo. 2009;23(1):155-161.

45. Arslan İnce FD, Atay A, Köseoğlu M, Yeşil M, Deveci E. Relationship between severity of coronary artery disease and apolipoprotein E gene polymorphism. Anadolu Kardiyol. Derg. 2010;10(3):202-208.

46. Fawzy MS, Toraih EA, Aly NM, Fakhr EA, Badran DI, Hussein MH. Atherosclerotic and thrombotic genetic and environmental determinants in Egyptian coronary artery disease patients: a pilot study. BMC Cardiovasc Disord. 2017;17(1):26. 